\title{
Development of polyaniline microarray electrodes for cadmium analysis ${ }^{\neq}$
}

\author{
Marta Oliveira, Subramanian Viswanathan, Simone Morais, Cristina Delerue-Matos
}

\begin{abstract}
Disposable screen-printed electrodes (SPCE) were modified using a cosmetic product to partially block the electrode surface in order to obtain a microelectrode array. The microarrays formed were electropolymerized with aniline. Scanning electron microscopy was used to evaluate the modified and polymerized electrode surface. Electrochemical characteristics of the constructed sensor for cadmium analysis were evaluated by cyclic and square-wave voltammetry. Optimized stripping procedure in which the preconcentration of cadmium was achieved by depositing at $-1.20 \mathrm{~V}$ (vs. $\mathrm{Ag} / \mathrm{AgCl}$ ) resulted in a well defined anodic peak at approximately $-0.7 \mathrm{~V}$ at $\mathrm{pH} 4.6$. The achieved limit of detection was $4 \times 10^{-9} \mathrm{~mol} \mathrm{dm}^{-3}$. Spray modified and polymerized microarray electrodes were successfully applied to quantify cadmium in fish sample digests.

Q 2012 Institute of Chemistry, Slovak Academy of Sciences
\end{abstract}

Keywords

screen-printed electrodes, microarray electrodes, aniline, cadmium

\section{Introduction}

Electrochemical methods are increasingly used in different applications such as disease diagnostics, toxic substance detection, agriculture, food processing, and environmental analysis (Hangarter et al., 2010; Kadara et al., 2009a; Orozco et al., 2010). Microelectrodes are a versatile tool showing unique properties due to their small size (Belmont et al., 1996; Choudhry et al., 2010b; Cugnet et al., 2009; Kadara et al., 2009b; Orozco et al., 2010; Štulík et al., 2000). Microarrays are single microelectrodes wired in parallel, with each electrode diffusionally independent, yielding a signal by many orders of magnitude larger compared to individual microelectrodes (Krishnamoorthy et al., 2009; Orozco et al., 2010). These microelectrodes are in a fixed distance from their nearest neighbor; alternatively, random arrays of microelectrodes termed as ensembles due to no regular spacing between the neighboring microelectrodes can be applied (Choudhry et al., 2010a, 2010b; Gornall et al., 2009). Electrochemical signal observed using the arrays cor- responds to the total signal of all electrodes comprising the array. Thus, a large analytical signal coupled with low background currents results in an increase of the analytical sensitivity allowing lower detection limits. Microelectrode arrays provide advantages such as high current densities, high temporal and spatial resolution, and reduced capacitive-charging currents; they also find use in environmental sensing particularly as analytical screening tools for heavy metals detection (Choudhry et al., 2010a; Honeychurch \& Hart, 2003; Kadara et al., 2009b; Orozco et al., 2010; DomínguezRenedo et al., 2007; Štulík et al., 2000). Since microarrays represent a large number of active discs, when the target analyte is in an analytically challenging medium such as an effluent containing surface passivating media, even though some microdiscs on the array become electrochemically inactive, the sensitivity is not severely affected due to the still high overall number of active discs. These microelectrode arrays can be produced using different methods (Štulík et al., 2000 ) such as photolithography (Feeney \& Kounaves, 2000; Orozco et al., 2010), sonochemical ablation of 
thin polymer films (Barton et al., 2004; Cugnet et al., 2009; Myler et al., 2004, 2005; Pritchard et al., 2004), or microdiscs in epoxy resin (Fletcher \& Horne, 1999).

One possibility of forming a highly active elec-trode area on a miniaturized sensor is electropolymerization. Polymer films, and particularly those based on substituted aromatic compounds, such as aniline, present interesting characteristics, namely high conductivity, stability, durability, and reproducibility associated with low costs (Bhadra et al., 2009; Casella \& Guascito, 1997; Gornall et al., 2009; Grennan et al., 2006; Huang et al., 2002, 2003; Šeděnková et al., 2008; Shan et al., 2008; Trashin et al., 2009; Waltman \& Bargon, 1986; Yin et al., 2006). Their main drawback is related to their preparation which involves handling of the respective monomers which are potentially hazardous materials.

Screen-printed electrodes are inexpensive and disposable electrodes with the potential to be applied in real life situations (Choudhry et al., 2009; Gornall et al., 2009; Honeychurch \& Hart, 2003; Kadara et al., 2009a, 2009b; Domínguez-Renedo et al., 2007). Nowadays, they are used as glucose or metal sensors (Choudhry et al., 2009; Florescu \& Brett, 2005; Kampouris et al., 2009; Piano et al., 2010). They also find application as biological sensors, $\mathrm{pH}$ sensors, and in food allergen detection (Arduini et al., 2010; Kadara et al., 2009a; Kampouris et al., 2009). Furthermore, screen-printed electrodes related instruments can be portable allowing in situ determination of heavy metals (Honeychurch \& Hart, 2003).

Cadmium is a non-essential element that accumulates in the human body negatively affecting several organs: liver, kidneys, lungs, bones, placenta, brain, and the central nervous system (Castro-González \& Méndez-Armenta, 2008). In general, for non-smokers and non-occupationally exposed individuals, food products account for most of the human exposure to cadmium (ExtoxNet, 2003). European Community Regulation (European Commission, 2006) settles the maximum level for cadmium in muscle of some fish species as $0.1 \mathrm{mg} \mathrm{kg}^{-1}$ (wet mass). Cugnet et al. (2009) and Khairy et al. (2010) developed various modifications of screen-printed electrodes for the quantification of $\mathrm{Cd}^{2+}$ while Choudhry et al. (2010a) presented a facile production of graphite microelectrodes ensembles based on a cosmetic spray modification. In this study, the development of a new screenprinted carbon microelectrode mechanically modified with a cosmetic product and electropolymerized with aniline is reported. The developed sensor was tested in fish sample analysis for trace $\mathrm{Cd}^{2+}$ determination.

\section{Experimental}

\section{Reagents and solutions}

Ultrapure water (resistivity of $18.2 \mathrm{M} \Omega \mathrm{cm}^{-1}$ ) was produced by a Milli-Q Simplicity 185 system (Millipore, Molsheim, France). Suprapure nitric acid (65\%, Merck, Darmstadt, Germany) and perchloric acid (70\%, Sigma-Aldrich, Steinheim, Germany) were used for the digestion of samples. All other reagents used were of analytical reagent grade (Merck, Darmstadt, Germany).

Supporting electrolyte for the electrochemical studies was the acetate buffer solution, $0.200 \mathrm{~mol} \mathrm{dm}^{-3}$, prepared by mixing $0.200 \mathrm{~mol} \mathrm{dm}^{-3}$ acetic acid (Carlo Erba, Val de Reuil, France) and $0.200 \mathrm{~mol} \mathrm{dm}^{-3}$ sodium acetate (Merck, Darmstadt, Germany). The buffer solution was contaminated with $5.84 \times 10^{-6}$ mol $\mathrm{dm}^{-3}$ mercury nitrate monohydrate (Fluka, Steinheim, Germany) and the $\mathrm{pH}$ of the solution was adjusted to 4.6 . A solution containing $0.100 \mathrm{~mol} \mathrm{dm}^{-3}$ $\mathrm{Fe}^{2+}$ (Fluka, Steinheim, Germany)/Fe $\mathrm{Fe}^{3+}$ (Riedel-de Häen, Seelze, Germany) and $0.100 \mathrm{~mol} \mathrm{dm}^{-3}$ potassium chloride (Riedel-de Häen, Seelze, Germany) was selected to study the electrochemical behavior of the prepared electrodes by cyclic voltammetry. Aniline (Sigma-Aldrich, Steinheim, Germany) and sulfuric acid (96\%, Panreac, Barcelona, Spain) were used for the electrode polymerization. Because aniline is a potentially hazardous material, personal protective (skin, eye, and respiratory) equipment should be used and handling should be obligatory done in a ventilated hood in order to avoid contact with liquid aniline or aniline vapors (BASF, 2008). Standard solution of cadmium was prepared daily by dilution of the stock solution $\left(8.89 \times 10^{-3} \mathrm{~mol} \mathrm{dm}^{-3}\right.$, Panreac, Barcelona, Spain). The cosmetic product Men Antiperspirant spray was obtained in a local market (Porto, Portugal). All glassware and polyethylene materials were soaked in nitric acid (10 vol. \%) for at least $24 \mathrm{~h}$, thoroughly rinsed with ultrapure water, and dried before use.

\section{Equipment}

A standard three electrodes cell and an AUTOLAB potentiostat/galvanostat, model PGSTAT12 (Methrom, Schiedam, The Netherlands), controlled by the GPES version 4.9 software were used for the electrochemical studies. Experiments were performed using working screen-printed carbon electrodes (SPCE; Dropsens, Spain; $4 \mathrm{~mm}$ of diameter) with an $\mathrm{Ag} / \mathrm{AgCl} / 3.00 \mathrm{~mol} \mathrm{dm}^{-3}$ potassium chloride reference electrode (to which all the potential values are referred) and a platinum wire counter electrode. The working solutions were purged with nitrogen (99.99\%, LINDE, Porto, Portugal).

Morphological characterization of the SPCE was carried out by scanning electron microscopy (SEM; microscope model FEI Quanta FEG, Eindhoven, The Netherlands) coupled with an X-ray microanalysis system on an energy dispersive spectrometer (EDX; EDX EDAX Pegasus X4M, Tilburg, The Netherlands). Ac- 
celeration voltage of $10 \mathrm{kV}$ was employed.

Microwave-assisted digestions were performed using a MARS-X, 1500 W Microwave Accelerated Reaction System for Digestion (CEM, Mathews, NC, USA) configured with a 14 position carousel. During the operation, both temperature and pressure were monitored (Vieira et al., 2011).

\section{Electrode modification}

Electrochemical pretreatment of SPCE was performed by the application of $1.5 \mathrm{~V}$ (vs. $\mathrm{Ag} / \mathrm{AgCl}$ ) for $60 \mathrm{~s}$ in $0.500 \mathrm{~mol} \mathrm{dm}^{-3}$ sulfuric acid. The electrode surface was then sprayed with a commercial deodorant Men Antiperspirant product from the distance of $200 \mathrm{~mm}$ for a selected modification time. The SPCE was dried for $10 \mathrm{~min}$ at $40^{\circ} \mathrm{C}$.

Electropolymerization on the micro gaps of the cosmetic spray modified SPCE was achieved with a 0.100 mol dm$~^{-3}$ aniline solution in $0.500 \mathrm{~mol} \mathrm{dm}^{-3}$ sulfuric acid (Trashin et al., 2009; Yin et al., 2006). Cyclic voltammetric scanning was performed in the range of $-0.2 \mathrm{~V}$ to $+0.8 \mathrm{~V}$ (vs. $\mathrm{Ag} / \mathrm{AgCl}$ ) at the scan rate of $100 \mathrm{mV} \mathrm{s}^{-1}$ in 50 cycles. Then, the polymerized SPCE was washed with ultrapure water and placed in acetate buffer for three to four days to neutralize and stabilize the polymer on the electrode surface.

\section{Fish sample analysis}

Fresh horse mackerel (Trachurus trachurus) samples from Northeast Atlantic Ocean were purchased from several markets in the Oporto metropolitan area (NW Portugal). Sample collection and preparation was performed in accordance with EPA Guide No. 823B-00-07 (2000) and EC Regulation No. 333/2007 (European Commission, 2007). The specimens were manually headed, eviscerated, skinned, and filleted. Each sample further quantified was constituted of fillets of at least four individuals and had the minimum mass of $200 \mathrm{~g}$ (Ramalhosa et al., 2012; Vieira et al., 2011). Samples (1.5 $\pm 0.1 \mathrm{~g}$ ) were placed into previously weighed Teflon vessels, and then dried in a microwave until three reproducible mass values were obtained. An aliquot of $10 \mathrm{~mL}$ of suprapure $\mathrm{HNO}_{3}$ was then added to each vessel containing ca. $0.5 \mathrm{~g}$ of sample dry mass and the microwave digestion proceeded for $35 \mathrm{~min}$ at $175{ }^{\circ} \mathrm{C}$. After digestion and cooling to ca. $30{ }^{\circ} \mathrm{C}$, samples were evaporated to dryness (Cerejeira Matos et al., 2009a, 2009b, 2010; Vieira et al., 2011). The residue was treated with an aliquot of $5 \mathrm{~mL}$ of perchloric acid at the boiling point for $2 \mathrm{~h}$. After complete evaporation of perchloric acid, the residue was redissolved in the supporting electrolyte for cadmium determination. Quantifications were achieved by the standard addition method. All measurements were performed at least in triplicate.

\section{Results and discussion}

\section{Spray modified SPCE}

First, SPCE were electrochemically activated with sulfuric acid at $1.5 \mathrm{~V}$ for $60 \mathrm{~s}$ in order to enhance their electrochemical response. According to previous studies (Kadara et al., 2009a; Gornall et al., 2009), this pretreatment decreases the static barrier, increases the surface functionality and roughness, and cleans the electrode surface. Then, the electrode surface was partly masked with an antiperspirant product and the new produced microelectrode array was characterized. Changes in the voltammetric profiles were observed using $\mathrm{Fe}(\mathrm{CN})_{6}^{3-/ 4-}$ as an electroactive indicator (Fig. 1). Cyclic voltammograms at $0.005 \mathrm{~V} \mathrm{~s}^{-1}$
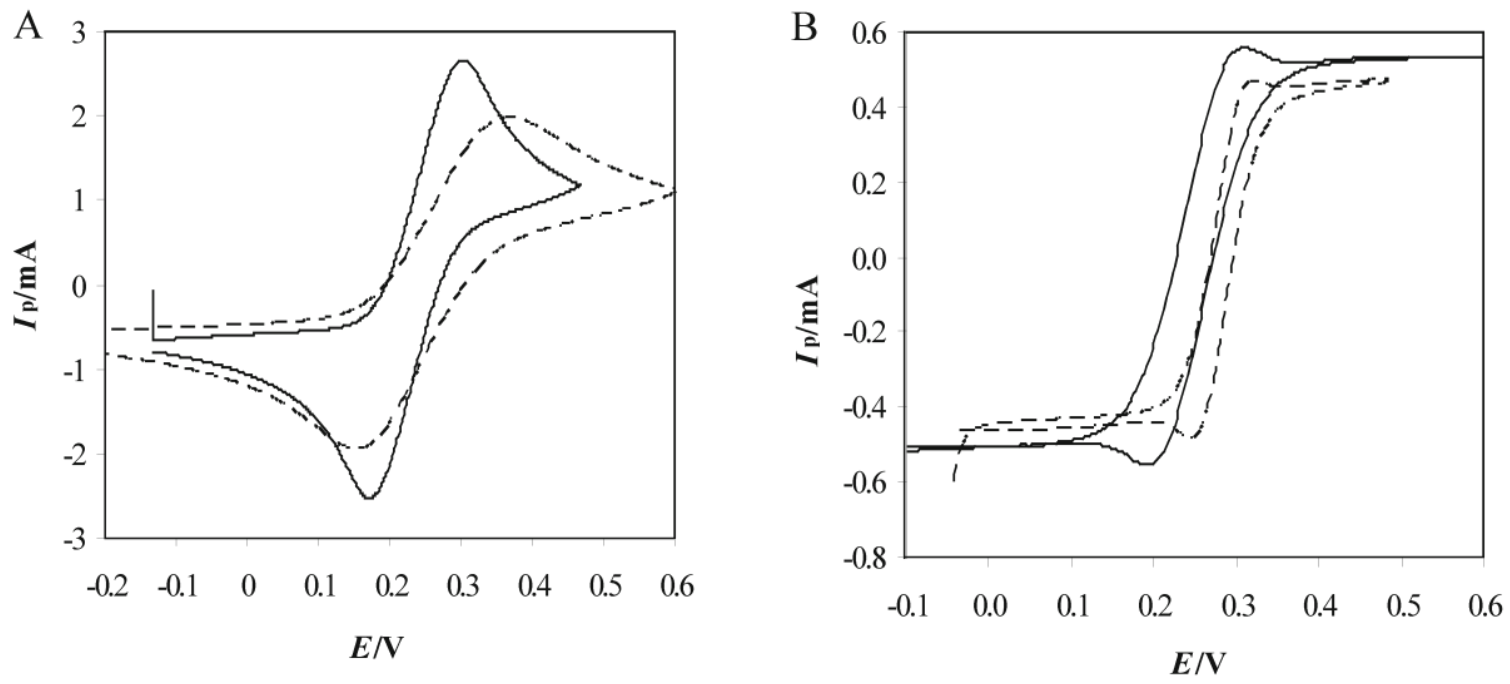

Fig. 1. Cyclic voltammograms at $0.100 \mathrm{~V} \mathrm{~s}^{-1}(\mathrm{~A})$ and $0.005 \mathrm{~V} \mathrm{~s}^{-1}$ (B) in $0.100 \mathrm{~mol} \mathrm{dm}-3 \mathrm{Fe}^{2+} / \mathrm{Fe}^{3+}$ with $0.1 \mathrm{~mol} \mathrm{dm} \mathrm{KCl}^{-3}$, obtained on bare SPCE (solid line) and SPCE modified with a cosmetic product for $8 \mathrm{~s}$ (dashed line). 


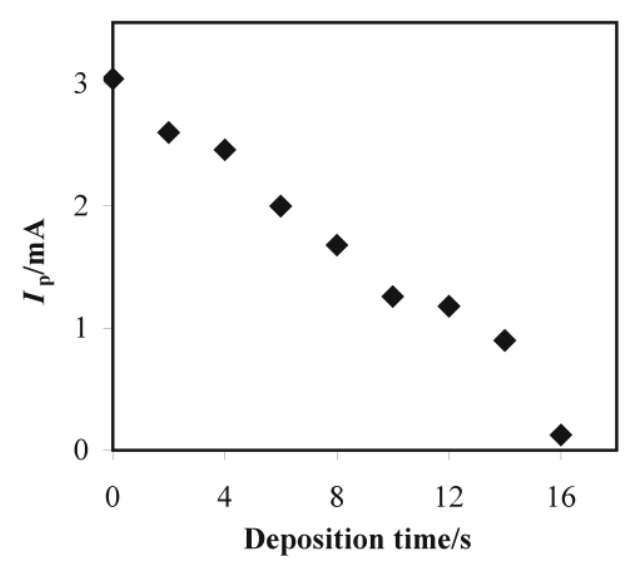

Fig. 2. Peak intensity against spray modification time applied to the electrode surface.

(Fig. 1B) revealed the microelectrode behavior as presented in other studies (Choudhry et al., 2010a; Huang et al., 2009; Kadara et al., 2009b). Increasing the spray time had a significant reduction effect on the peak intensity and the peak-to-peak separation revealing that the cosmetic spray reduced the amount of accessible graphite (Figs. 1 and 2). The time of $8 \mathrm{~s}$ was selected as the optimum modification time in order to turn the electrode into a partially blocked electrode with numerous graphite microdomains.

\section{Spray modified and aniline polymerized SPCE}

PANI is a polymer obtained from aniline (an oxidant and a strong mineral acid dopant) that has been successfully used in the construction of sensors (Huang et al., 2002; Sazou \& Georgolios, 1997; Trashin et al., 2009; Yin et al., 2006); its applications are limited to acidic media (Grennan et al., 2006; Karyakin et al., 1996). According to previous reports, a more efficient way of attaining reproducible film properties is using electrochemical oxidation. During polymerization (Fig. 3), this polymer presents two peaks. The sen-

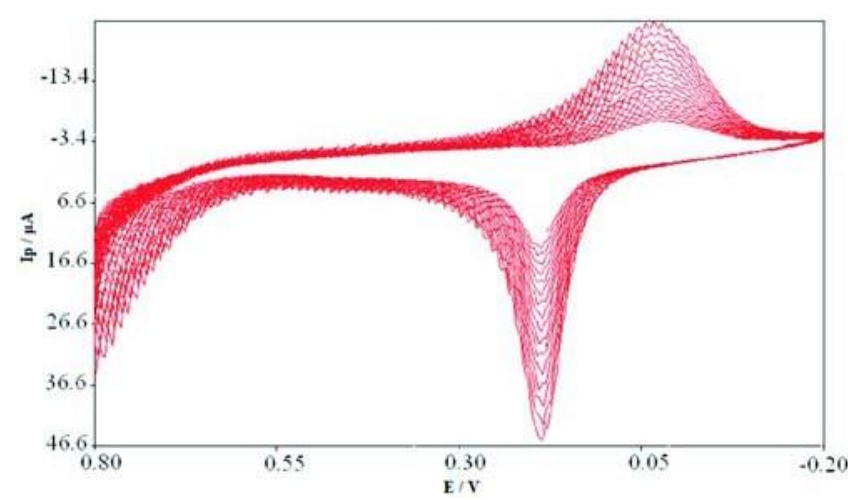

Fig. 3. Electropolymerization on micro gaps of cosmetic spray modified SPCE in the $0.100 \mathrm{~mol} \mathrm{dm}^{-3}$ aniline and 0.5 mol $\mathrm{dm}^{-3} \mathrm{H}_{2} \mathrm{SO}_{4}$ solution; $V_{\mathrm{i}}=-0.2 \mathrm{~V} ; V_{\mathrm{f}}=0.8 \mathrm{~V}$ (vs. $\mathrm{Ag} / \mathrm{AgCl} ; 3 \mathrm{~mol} \mathrm{dm}^{-3} \mathrm{KCl}$ ); scan rate $=0.1 \mathrm{~V} \mathrm{~s}^{-1}$; 50 cycles.

sitivity reached by a PANI based sensor is directly related to the background current of the conducting polymer which depends on the film structure and thickness. Electrochemical polymerization permits the control of the amount deposited, i.e. the thickness of the film, by the number of cycles, and the desired amount of charge (Grennan et al., 2006; Trashin et al., 2009; Waltman \& Borgon, 1986).

In the present work, modified SPCEs were electropolymerized with aniline in 50 cycles and for each polymerized electrode, the peak intensities were monitored. Thermal stability of nanoscale thickness PANI films is affected by high temperatures (Brožová et al., 2008; Šeděnková et al., 2008). As so, the preparation and subsequent stabilization of the polymerized SPCEs was performed at ambient temperature (ca. $\left.23{ }^{\circ} \mathrm{C}\right)$.

Some previous studies (Kadara et al., 2009a, $2009 \mathrm{~b}$ ) regarding SPCEs showed that the geometric area is higher than the real electrochemical area because of the polymer attached to the graphite particles. SEM images of bare (un-treated), cosmetic spray modified, and aniline polymerized SPCE surfaces were
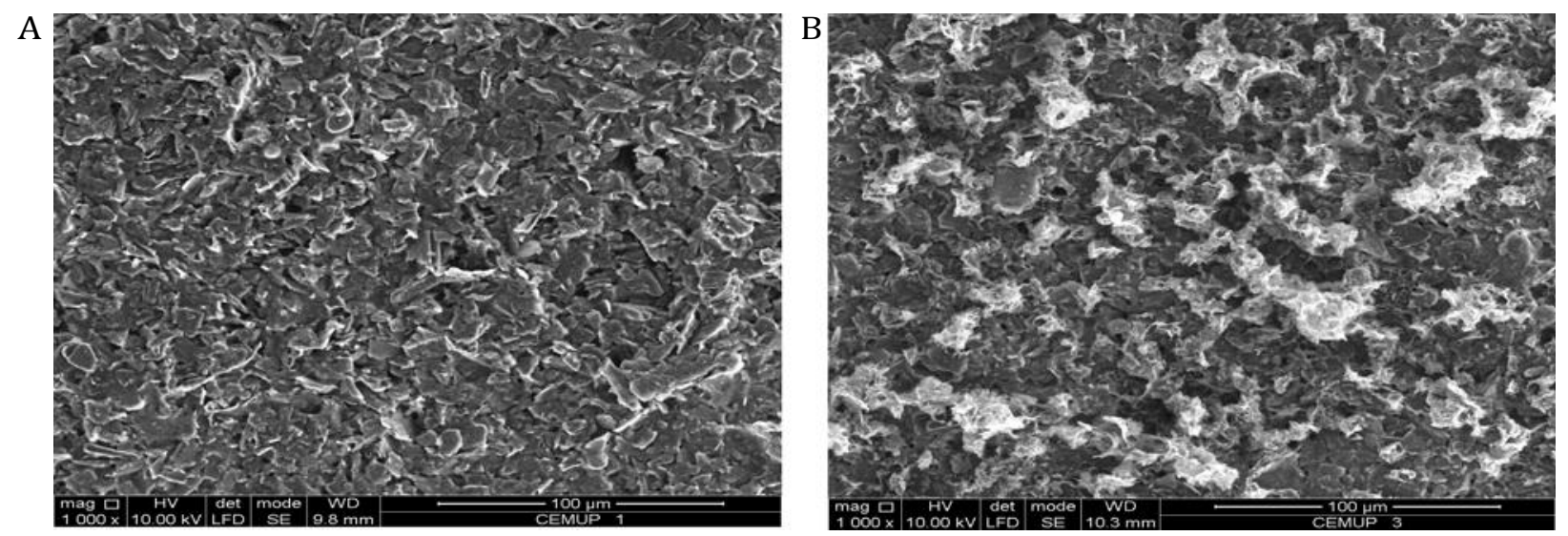

Fig. 4. Scanning electron micrographs $(\times 1000)$ of bare SPCE $(A)$ and modified and aniline polymerized SPCE (B). 
Table 1. Characterization of electro-active areas of the bare, spray modified, and modified and aniline polymerized SPCE

\begin{tabular}{lccc}
\hline SPCE & $A_{\text {geom }} / \mathrm{cm}^{2}$ & $A_{\text {elect }} / \mathrm{cm}^{2}$ & $A_{\text {real }} / \mathrm{cm}^{2}$ \\
\hline Unactivated bare & - & 0.068 & 0.543 \\
Activated bare & 0.126 & 0.122 & 0.970 \\
Spray modified & - & 0.061 & 0.484 \\
Spray modified & - & 0.125 & 0.998 \\
$\quad$ and polymerized & & & \\
\hline
\end{tabular}

analyzed in order to complete the data obtained from voltammetric studies. Results are presented in Fig. 4. The surface of bare SPCE (Fig. 4A) is composed of flakes of graphite with various diameters, all in the micrometer range, which is in accordance with previously published results (Choudhry et al., 2010a; Gornall et al., 2009; Kadara et al., 2009a). From the comparison of bare and spray modified SPCE (data not shown), it can be concluded that the polymer present in the cosmetic spray filled in the gaps and reduced the amount of accessible graphite, which accounts for the reduction in the voltammetric peak current when the spray modification time was increased (Fig. 2). The presence of small clusters of polymer was also observed. SEM image of the modified and polymerized SPCE (Fig. 4B) revealed its different structure from the spray modified electrode, with the bright "cauliflowerlike" appearance in accordance to the study presented by Huang et al. (1986) and Grennan et al. (2006).

The obtained electrochemical profiles of bare, modified and polymerized SPCE in $0.100 \mathrm{~mol} \mathrm{dm}^{-3}$ $\mathrm{Fe}^{2+} / \mathrm{Fe}^{3+}$ are presented in Fig. 5. Active electrode areas $\left(A_{\text {elect }}\right)$ of bare SPCE and the spray modified and polymerized one were estimated applying the theoretical Randles-Sevčik equation for the quasi-reversible electron transfer process (Table 1) (Greef et al., 1993). The real area $\left(A_{\text {real }}\right)$ indicates the effective electrochemically activated area and it can be determined by the following relation: $A_{\text {real }}=A_{\text {elect }} / A_{\text {geom }}$, where $A_{\text {geom }}$ is the geometric area of the electrode estimated based on the working electrode radius (Table 1 ) (Cugnet et al., 2009; Kadara et al., 2009a). The working electrode area almost doubled its size from the unactivated bare to the activated bare electrode which is in accordance with previous studies (Gornall et al., 2009; Kadara et al., 2009a). It can be observed that the cosmetic spray modified SPCE had a smaller surface than the bare SPCE, as it can be seen in Fig. $5 b$. When polymerized, SPCE has a slightly higher working area than the bare electrode (Fig. 5c).

\section{Cadmium analysis}

To date, one of the main interests of SPCEs concerns their use in stripping analysis using mer-

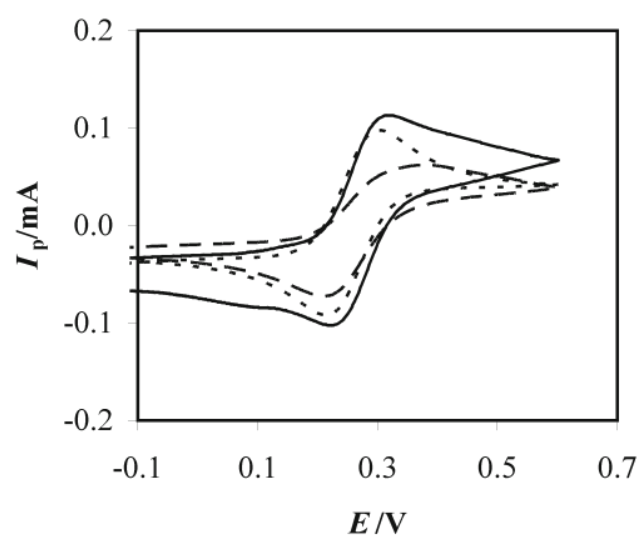

Fig. 5. Cyclic voltammograms of bare (dotted line), cosmetic spray modified (dashed line), and modified and aniline polymerized SPCE (solid line) in $0.100 \mathrm{~mol} \mathrm{dm}^{-3}$ $\mathrm{Fe}^{2+} / \mathrm{Fe}^{3+}$ at the scan rate of $0.01 \mathrm{~V} \mathrm{~s}^{-1} ; V_{\mathrm{i}}=-0.3$ $\mathrm{V} ; V_{\mathrm{f}}=0.6 \mathrm{~V}$ (vs. Ag/AgCl; $3 \mathrm{~mol} \mathrm{dm}^{-3} \mathrm{KCl}$ ).

cury to obtain an amalgam with the electrodeposited metal (Honeychurch \& Hart, 2003). In this study, the prepared spray modified and aniline polymerized SPCE was tested for cadmium analysis by squarewave voltammetry. The main analytical parameters, namely mercury film quality and anodic stripping voltammetry conditions, were optimized in order to reach maximum sensitivity. Since SPCE microarrays have a small area, highly diluted mercury solution was used $\left(5.84 \times 10^{-6} \mathrm{~mol} \mathrm{dm}^{-3}\right)$ in order to suppress the undesirable background signal. The best sensitivity was achieved using the conditioning potential of $0.6 \mathrm{~V}$, conditioning and deposition time of $120 \mathrm{~s}$ at $-1.2 \mathrm{~V}$ (vs. $\mathrm{Ag} / \mathrm{AgCl}$ ), square-wave frequency of $25 \mathrm{~Hz}$, step potential of $0.005 \mathrm{~V}$, and the amplitude of $0.020 \mathrm{~V}$. Cadmium peak heights, determined using the spray modified and PANI polymerized SPCE, showed a linear response over the range from $3.30 \times 10^{-8}$ mol dm$~^{-3}$ to $7.12 \times 10^{-8} \mathrm{~mol} \mathrm{dm}^{-3}$ (Fig. 6), which is lower than the range reported by Khairy et al. (2010) $\left(8.90 \times 10^{-7} \mathrm{~mol} \mathrm{dm}^{-3}\right.$ to $\left.7.12 \times 10^{-6} \mathrm{~mol} \mathrm{dm}^{-3}\right)$ for a bismuth film modified screen printed electrode (SPE). The limit of detection (LOD) and the limit of quantification (LOQ) were calculated as the concentration corresponding to three and ten times, respectively, the standard deviation of the blank divided by the slope of the calibration curve (Miller \& Miller, 2000). The limits achieved in this work ( $4 \times 10^{-9} \mathrm{~mol} \mathrm{dm}^{-3}$ and $1 \times 10^{-8} \mathrm{~mol} \mathrm{dm}^{-3}$ for LOD and LOQ, respectively) are lower than the values presented by Cugnet et al. (2009) and Khairy et al. (2010). The lower detection and quantification limits obtained with this type of electrodes are promoted by the combination of microarrays and SPE properties (Kadara et al., 2009b). Also, the developed methodology is appropriate for quality control according to water and food analysis legislation of the European Union (European Commission, 2006). 


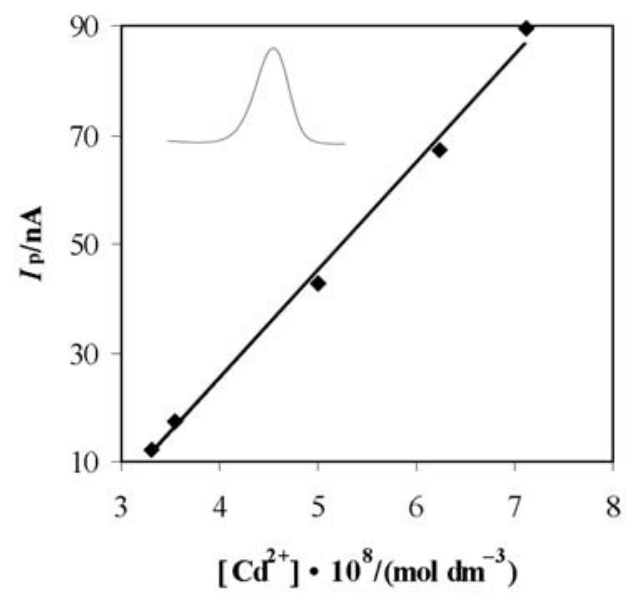

Fig. 6. Calibration plot $\left(I_{\mathrm{P}} / \mathrm{nA}=1.99 \times 10^{9}\left[\mathrm{Cd}^{2+}\right] /(\mathrm{mol}\right.$ $\left.\left.\mathrm{dm}^{-3}\right)-54.4, R^{2}=0.996\right)$ of cadmium $\left(3.30 \times 10^{-8}\right.$ $\mathrm{mol} \mathrm{dm} \mathrm{dm}^{-3}$ to $7.12 \times 10^{-8} \mathrm{~mol} \mathrm{dm}^{-3}$ ) in acetate buffer $\left(0.2 \mathrm{~mol} \mathrm{dm}^{-3}, \mathrm{pH} \mathrm{4.6)}\right.$ for a spray modified and aniline polymerized SPCE. Experimental conditions: conditioning potential of $0.6 \mathrm{~V}$ (vs. Ag/AgCl); deposition potential of $-1.20 \mathrm{~V}$; conditioning and deposition time of $120 \mathrm{~s}$, frequency of $25 \mathrm{~Hz}$.

Field applicability of the prepared SPCE was also estimated by analyzing the content of cadmium in the digested horse mackerel fillet samples. According to FAO (2003), horse mackerel is an underutilized medium fat content pelagic fish, abundant in Atlantic Ocean. It is an inexpensive fish highly appreciated by most West-European populations, especially in Holland, Ireland, Spain, France, Germany, and Portugal (Losada et al., 2005). The mean cadmium concentration of $(0.0389 \pm 0.0013) \mathrm{mg}$ per $\mathrm{kg}$ of wet mass was obtained which is in accordance with the value determined by the high-resolution continuum source graphite furnace atomic absorption spectrometry (Vieira et al., 2011). A recovery experiment was also performed, in triplicate, on the digested fish sample and the value of $(104.8 \pm 6.1) \%$ was obtained. Although other heavy metals, such as lead ( (0.0031 \pm 0.0003$) \mathrm{mg}$ per kg of wet mass) mercury $((0.2198 \pm 0.0086) \mathrm{mg}$ per kg of wet mass $)$, and metalloid arsenic ( $(0.9539 \pm 0.0242) \mathrm{mg}$ per $\mathrm{kg}$ of wet mass) were detected in the fish sample by graphite furnace atomic absorption spectrometry at different concentration levels, no significant interferences were observed. The mean cadmium concentration determined in horse mackerel fillets is far below the maximum level ( $0.10 \mathrm{mg}$ per kg of wet mass) established by the European Community regulation (European Commission, 2006) indicating that there is no health risk for the consumers.

\section{Conclusions}

This study presents the development and characterization of polyaniline microarray electrodes for cad- mium quantification. Surface modifications were performed on carbon screen-printed electrodes applying a cosmetic product and the electropolymerization with aniline. Linearity was observed over the range from $3.30 \times 10^{-8} \mathrm{~mol} \mathrm{dm}^{-3}$ to $7.12 \times 10^{-8} \mathrm{~mol} \mathrm{dm}^{-3}$. The obtained limit of detection was $4 \times 10^{-9} \mathrm{~mol} \mathrm{dm}^{-3}$. Applicability of the developed sensor was verified by the determination of cadmium in fish digests. Acceptable accuracy and recovery $((104.8 \pm 6.1) \%)$ were reached.

Acknowledgements. This work was supported by the Fundac,ão para a Ci^encia e a Tecnologia through the project PTDC/AGR-AAM/102316/2008 (COMPETE and co-financed by FEDER) and the Grant no. PEst-C/EQB/LAOOO6/2011.

\section{References}

Arduini, F., Amine, A., Majorani, C., Di Giorgio, F., De Felicis, D., Cataldo, F., Moscone, D., \& Palleschi, G. (2010). High performance electrochemical sensor based on modified screen-printed electrodes with cost-effective dispersion of nanostructured carbon black. Electrochemistry Communications, 12, 346-350. DOI: 10.1016/j.elecom.2009.12.028.

Barton, A. C., Collyer, S. D., Davis, F., Gornall, D. D., Law, K. A., Lawrence, E. C. D., Mills, D. W., Myler, S., Pritchard, J. A., Thompson, M., \& Higson, S. P. J. (2004). Sonochemically fabricated microelectrode arrays for biosensors offering widespread applicability Part I. Biosensors \& Bioelectronics, 20, 328-337. DOI: 10.1016/j.bios.2004.02.002.

BASF (2008). Product safety summary: aniline. Retrieved on October 26, 2011, from http://basf.com/group/corporate/us/ en/function/conversions:/publish/content/about-basf/ worldwide/northamerica/USA/sustainability/rc/docs/ AnilineProductSafetySummary.pdf

Belmont, C., Tercier, M. L., Buffle, J., Fiaccabrino, G. C., \& Koudelka-Hep, M.(1996). Mercury-plated iridium-based microelectrode arrays for trace metals detection by voltammetry: optimum conditions and reliability. Analytica Chimica Acta, 329, 203-214. DOI: 10.1016/0003-2670(96)00116-x.

Bhadra, S., Khastgir, D., Singha N. K., \& Lee, J. H. (2009). Progress in preparation, processing and applications of polyaniline. Progress in Polymer Science, 34, 783-810. DOI: 10.1016/j.progpolymsci.2009.04.003.

Brožová, L., Holler, P., Kovářová, J., Stejskal, J., \& Trchová, M. (2008). The stability of polyaniline in strongly alkaline or acidic aqueous media. Polymer Degradation and Stability, 93, 592-600. DOI: 10.1016/j.polymdegradstab.2008.01.012.

Cerejeira Matos, R., Vieira, C., Morais, S., Pereira, M. L., \& Pedrosa de Jesus, J. (2009a). Nephrotoxicity of CCA-treated wood: A comparative study with $\mathrm{As}_{2} \mathrm{O}_{5}$ and $\mathrm{CrO}_{3}$ on mice. Environmental Toxicology and Pharmacology, 27, 259-263. DOI: 10.1016/j.etap.2008.11.009.

Cerejeira Matos, R., Vieira, C., Morais, S., Pereira, M. L., \& Pedrosa, J. (2009b). Nephrotoxicity effects of the wood preservative chromium copper arsenate on mice: Histopathological and quantitative approaches. Journal of Trace Elements in Medicine and Biology, 23, 224-230. DOI: 10.1016/j.jtemb.2009.03.008.

Cerejeira Matos, R., Vieira, C., Morais, S., Pereira, M. L., \& Pedrosa, J. (2010). Toxicity of chromated copper arsenate: A study in mice. Environmental Research, 110,424-427. DOI: 10.1016/j.envres.2010.03.001.

Casella, I. G., \& Guascito, M. R. (1997). Electrocatalysis of ascorbic acid on the glassy carbon electrode chemically mod- 
ified with polyaniline films. Electroanalysis, 9, 1381-1386. DOI: 10.1002/elan.1140091802.

Castro-González, M. I., \& Méndez-Armenta, M. (2008). Heavy metals: Implications associated to fish consumption. Environmental Toxicology and Pharmacology, 26, 263-271. DOI: 10.1016/j.etap.2008.06.001.

Choudhry, N. A., Kadara, R. O., \& Banks, C. E. (2010a). “Cosmetic electrochemistry": the facile production of graphite microelectrode ensembles. Physical Chemistry Chemical Physics, 12, 2285-2287. DOI: 10.1039/b923246j.

Choudhry, N. A., Kadara, R. O., Jenkinson, N., \& Banks, C. E. (2010b). Screen printed electrodes provide microdomain sites for fabricating disposable electro-catalytic ensembles. Electrochemistry Communications, 12, 406-409. DOI: 10.1016/j.elecom.2010.01.005.

Choudhry, N. A., Kampouris, D. K., Kadara, R. O., Jenkinson, N., \& Banks, C. E. (2009). Next generation screen printed electrochemical platforms: Non-enzymatic sensing of carbohydrates using copper(II) oxide screen printed electrodes. Analytical Methods, 1, 183-187. DOI: 10.1039/b9ay00095j.

Cugnet, C., Zaouak, O., René, A., Pécheyran, C., Potin-Gautier, M., \& Authier, L. (2009). A novel microelectrode array combining screen-printing and femtosecond laser ablation technologies: Development, characterization and application to cadmium detection. Sensors and Actuators B: Chemical, 143, 158-163. DOI: 10.1016/j.snb.2009.07.059.

Domínguez-Renedo, O., Alonso-Lomillo, M. A., \& Arcos Martínez, M. J. (2007). Recent developments in the field of screenprinted electrodes and their related applications. Talanta, 73, 202-219. DOI: 10.1016/j.talanta.2007.03.050.

European Commission (2006). Commission regulation (EC) No 1881/2006 of 19 December 2006 setting maximum levels for certain contaminants in foodstuffs. Official Journal of the European Union, 2006, L 364/5-L 364/24.

European Commission (2007). Regulation (EC) No 333/2007 of 28 March 2007 laying down the methods of sampling and analysis for the official control of the levels of lead, cadmium, mercury, inorganic tin, 3-MCPD and benzo(a)pyrene in foodstuffs. Official Journal of the European Union, 2007, L 88/29-L 88/38.

FAO (2003). FAO yearbook of fishery statistics (Vol. 92(1), pp. 250-252). Rome, Italy: Food and Agriculture Organization of the United Nations.

Feeney, R., \& Kounaves, S. P. (2000). Microfabricated ultramicroelectrode arrays: Developments, advances, and applications in environmental analysis. Electroanalysis, 12, 677-684. DOI: 10.1002/1521-4109(200005).

Fletcher, S., \& Horne, M. D. (1999). Random assemblies of microelectrodes (RAM ${ }^{T M}$ electrodes) for electrochemical studies. Electrochemistry Communications, 1, 502-512. DOI: 10.1016/s1388-2481(99)00100-9.

Florescu, M., \& Brett, C. M. A. (2005). Development and evaluation of electrochemical glucose enzyme biosensors based on carbon film electrodes. Talanta, 65, 306-312. DOI: 10.1016/j.talanta.2004.07.003.

Gornall, D. D., Collyer, S. D., \& Higson, S. P. J. (2009). Investigations into the use of screen-printed carbon electrodes as templates for electrochemical sensors and sonochemically fabricated microelectrode arrays. Sensors and Actuators B: Chemical, 141, 581-591. DOI: 10.1016/j.snb.2009.06.051.

Greef, R., Peat, R., Peter, L. M., Pletcher, D., \& Robinson, J. (1993). Instrumental methods in electrochemistry. Chichester, UK: Ellis Horwood.

Grennan, K., Killard, A. J., Hanson, C. J., Cafolla, A. A., \& Smyth, M. R. (2006). Optimisation and characterisation of biosensors based on polyaniline. Talanta, 68, 1591-1600. DOI: $10.1016 /$ j.talanta.2005.08.036.
Hangarter, C. M., Bangar, M., Mulchandani, A., \& Myung, N. V. (2010). Conducting polymer nanowires for chemiresistive and FET-based bio/chemical sensors. Journal of Materials Chemistry, 20, 3131-3140. DOI: 10.1039/b915717d.

Honeychurch, K. C., \& Hart, J. P. (2003). Screen-printed electrochemical sensors for monitoring metal pollutants. TrAC Trends in Analytical Chemistry, 22, 456-469. DOI: 10.1016/s0165-9936(03)00703-9.

Huang, W. S., Humphrey, B. D., \& MacDiarmid, A. G. (1986). Polyaniline, a novel conducting polymer. Morphology and chemistry of its oxidation and reduction in aqueous electrolytes. Journal of the Chemical Society, Faraday Transactions I, 82, 2385-2400. DOI: 10.1039/f19868202385.

Huang, X. J., O'Mahony, A. M. \& Compton, R. G. (2009). Microelectrode arrays for electrochemistry: Approaches to fabrication. Small, 5, 776-788. DOI: 10.1002/smll.200801593.

Huang, J. X., Virji, S., Weiller, B. H., \& Kaner, R. B. (2003). Polyaniline nanofibers: Facile synthesis and chemical sensors. Journal of the American Chemical Society, 125, 314-315. DOI: $10.1021 /$ ja028371y.

Huang, L. M., Wang, Z. B., Wang, H. T., Cheng, X. L., Mitra, A., \& Yan, Y. S. (2002). Polyaniline nanowires by electropolymerization from liquid crystalline phases. Journal of Materials Chemistry, 12, 388-391. DOI: 10.1039/b107499g.

Kadara, R. O., Jenkinson, N., \& Banks, C. E. (2009a). Characterisation of commercially available electrochemical sensing platforms. Sensors and Actuators B: Chemical, 138, 556562. DOI: 10.1016/j.snb.2009.01.044.

Kadara, R. O., Jenkinson, N., \& Banks, C. E. (2009b). Characterization and fabrication of disposable screen printed microelectrodes. Electrochemistry Communications, 11, 13771380. DOI: 10.1016/j.elecom.2009.05.010.

Kampouris, D. K., Kadara, R. O., Jenkinson, N., \& Banks, C. E. (2009). Screen printed electrochemical platforms for $\mathrm{pH}$ sensing. Analytical Methods, 1,25-28. DOI: 10.1039/b9ay00025a. Karyakin, A. A., Maltsev, I. A., \& Lukachova, L. V. (1996). The influence of defects in polyaniline structure on its electroactivity: optimization of 'self-doped' polyaniline synthesis. Journal of Electroanalytical Chemistry, 402, 217-219. DOI: 10.1016/0022-0728(95)04303-9.

Khairy, M., Kadara, R. O., Kampouris, D. K., \& Banks, C. E. (2010). In situ bismuth film modified screen printed electrodes for the bio-monitoring of cadmium in oral (saliva) fluid. Analytical Methods, 2, 645-649. DOI: 10.1039/c0ay00 056f.

Krishnamoorthy, G., Carlen, E. T., Beusink, J. B., Schasfoort, R. B. M., \& van den Berg, A. (2009). Single injection microarray-based biosensor kinetics. Analytical Methods, 1, 162-169. DOI: 10.1039/b9ay00176j.

Losada, V., Piñeiro, C., Barros-Velázquez, J., \& Aubourg, S. P. (2005). Inhibition of chemical changes related to freshness loss during storage of horse mackerel (Trachurus trachurus) in slurry ice. Food Chemistry, 93, 619-625. DOI: 10.1016/j.foodchem.2004.09.041.

Miller, J. N., \& Miller, J. C. (2000). Statistics and chemometrics for analytical chemistry (4th ed.). Harlow, UK: Pearson Education.

Myler, S., Collyer, S. D., Davis, F., Gornall, D. D., \& Higson, S. P. J. (2005). Sonochemically fabricated microelectrode arrays for biosensors: Part III. AC impedimetric study of aerobic and anaerobic response of alcohol oxidase within polyaniline. Biosensors \& Bioelectronics, 21 , 666-671. DOI: 10.1016/j.bios.2004.12.012.

Myler, S., Davis, F., Collyer, S. D., \& Higson, S. P. J. (2004). Sonochemically fabricated microelectrode arrays for biosensors-Part II. Modification with a polysiloxane coating. Biosensors \& Bioelectronics, 20, 408-412. DOI: 10.1016/j.bios.2004.02.009. 
Orozco, J., Fernández-Sánchez, C., \& Jiménez-Jorquera, C. (2010). Ultramicroelectrode array based sensors: A promising analytical tool for environmental monitoring. Sensors, 10, 475-490. DOI: 10.3390/s100100475.

Piano, M., Serban, S., Biddle, N., Pittson, R., Drago, G. A., \& Hart, J. P. (2010). A flow injection system, comprising a biosensor based on a screen-printed carbon electrode containing Meldola's Blue-Reinecke salt coated with glucose dehydrogenase, for the measurement of glucose. Analytical Biochemistry, 396, 269-274. DOI: 10.1016/j.ab.2009.09.028.

Pritchard, J., Law, K., Vakurov, A., Millner, P., \& Higson, S. P. J. (2004). Sonochemically fabricated enzyme microelectrode arrays for the environmental monitoring of pesticides. Biosensors \& Bioelectronics, 20, 765-772. DOI: 10.1016/j.bios.2004.06.008.

Ramalhosa, M. J., Paíga, P., Morais, S., Alves, M. R., DelerueMatos, C., \& Oliveira, M. B. P. P. (2012). Lipid content of frozen fish: Comparison of different extraction methods and variability during freezing storage. Food Chemistry, 131, 328-336. DOI: 10.1016/j.foodchem.2011.07.123.

Sazou, D., \& Georgolios, C. (1997). Formation of conducting polyaniline coatings on iron surfaces by electropolymerization of aniline in aqueous solutions. Journal of Electroanalytical Chemistry, 429, 81-93. DOI: 10.1016/s00220728(96)05019-x.

Šeděnková, I., Prokeš, J., Trchová, M., \& Stejskal, J. (2008). Conformational transition in polyaniline films - Spectroscopic and conductivity studies of ageing. Polymer Degradation and Stability, 93, 428-435. DOI: 10.1016/j.polymdegradstab.2007. 11.015.

Shan, D., Wang, S. X., He, Y. Y., \& Xue, H. G. (2008). Amperometric glucose biosensor based on in situ electropolymerized polyaniline/poly(acrylonitrile-co-acrylic acid) composite film. Materials Science \& Engineering C: Biomimetic and Supramolecular Systems, 28, 213-217. DOI: 10.1016/j.msec. 2006.12.003.
Štulík, K., Amatore, C., Holub, K., Mareček, V., \& Kutner, W. (2000). Microelectrodes. Definitions, characterization and applications. Pure and Applied Chemistry, 72, 1483-1492. DOI: $10.1351 /$ pac200072081483.

Trashin, S. A., Haltrich, D., Ludwig, R., Gorton, L., \& Karyakin, A. A. (2009). Improvement of direct bioelectrocatalysis by cellobiose dehydrogenase on screen printed graphite electrodes using polyaniline modification. Bioelectrochemistry, 76, 87-92. DOI: 10.1016/j.bioelechem.2009.06. 004.

US EPA (2000). Guidance for assessing chemical contaminant data for use in fish advisories. Fish sampling and analysis (Vol. 1, 3rd ed.). Washington, DC.

Vieira, C., Morais, S., Ramos, S., Delerue-Matos, C., \& Oliveira, M. B. P. P. (2011). Mercury, cadmium, lead and arsenic levels in three pelagic fish species from the Atlantic Ocean: Intraand inter-specific variability and human health risks for consumption. Food and Chemical Toxicology, 49, 923-932. DOI: 10.1016/j.fct.2010.12.016.

Waltman, R. J., \& Bargon, J. (1986). Electrically conducting polymers: a review of the electropolymerization reaction, of the effects of chemical structure on polymer film properties, and of applications towards technology. Canadian Journal of Chemistry - Revue Canadienne de Chimie, 64, 76-95. DOI: 10.1139/v86-015.

Yin, T. J., Wei, W. Z., \& Zeng, J. X. (2006). Selective detection of dopamine in the presence of ascorbic acid by use of glassy-carbon electrodes modified with both polyaniline film and multi-walled carbon nanotubes with incorporated $\beta$-cyclodextrin. Analytical \& Bioanalytical Chemistry, 386, 2087-2094. DOI: 10.1007/s00216-006-0845-z. 